\title{
Efeito da adição de glutationa peroxidase e cisteína ao diluidor de congelação do sêmen equino
}

\author{
[Effect of glutathione peroxidase and cysteine addition in an equine frozen semen medium] \\ L.O. Barros, S.V. Silva, F.C. Almeida, E.C.B. Silva, G.F. Carneiro, M.M.P. Guerra* \\ Universidade Federal Rural de Pernambuco - UFRPE - Recife, PE
}

\begin{abstract}
RESUMO
Foram utilizados ejaculados $(n=25)$ de garanhões para avaliar o efeito de glutationa peroxidase (GPx) e cisteína na viabilidade de espermatozoides congelados. O sêmen foi diluído em Botu Crio, com antioxidantes, e foram formados os grupos: G1, Controle; G2, 1U GPx ; G3, 5U GPx; G4, 0,5mM cisteína; G5, $1 \mathrm{mM}$ cisteína. Depois foi envasado em palhetas $(0,5 \mathrm{~mL})$ e congelado. Após descongelação, $37^{\circ} \mathrm{C}$ por 30 segundos, alíquotas foram analisadas quanto à integridade de membrana plasmática (IMP) e acrossoma (IAc), potencial de membrana mitocondrial (PMM) e cinética, nos tempos zero (T0) e 60 minutos (T60). GPx $5 \mathrm{U}$ e cisteína $0,5 \mathrm{mM}$ determinaram maior $(\mathrm{P}<0,05)$ IAc em T0 do que em T60. Cisteína $1 \mathrm{mM}$ resultou em maior $(\mathrm{P}<0,05)$ IAc em T60 do que GPx 1 e $5 \mathrm{U}$ e cisteína $0,5 \mathrm{mM}$. O PMM de um garanhão no T60 foi mais alto $(\mathrm{P}<0,05)$ do que o de dois garanhões. VCL e VAP foram maiores $(\mathrm{P}<0,05)$ no T0 do que no T60 do grupo controle, e um garanhão apresentou, em geral, valores cinéticos mais altos $(\mathrm{P}<0,05)$ do que os demais. Conclui-se que a adição de glutationa peroxidase, nas concentrações de $1 \mathrm{U}$ e $5 \mathrm{U}$, e de cisteína, nas concentrações de $0,5 \mathrm{mM}$ e $1 \mathrm{mM}$, não interferem na integridade de espermatozoides criopreservados de equinos, mas preservam os parâmetros cinéticos de VCL e VAP após 60 minutos de incubação. Ressalta-se, ainda, que o garanhão tem uma forte influência nas características espermáticas pós-congelação.
\end{abstract}

Palavras-chave: equino, antioxidantes, espermatozoide, criopreservação

\begin{abstract}
Ejaculates ( $n=25$ ) of horses were used to assess the effect of glutathione peroxidase (GPx) and cysteine on the viability of frozen sperm cells. Semen was extended at Botu Crio with antioxidants, and divided in groups: G1, control; G2, 1 U GPx; G3, 5U GPx; G4, 0.5mM cysteine and G5, 1mM cysteine, packed in $0.5 \mathrm{~mL}$ straws, and frozen. After thawing $\left(37^{\circ} \mathrm{C}\right.$ for 30 seconds) samples were analyzed for plasma membrane (IMP) and acrosome integrity (IAc), mitochondrial membrane potential (MMP) and kinematic, at zero (TO) and 60 minutes after (T60). GPx $5 U$ and cysteine $0.5 \mathrm{mM}$ increased $(P<0.05)$ IAc at T0, when compared to T60. Cysteine $1 \mathrm{mM}$ resulted in a higher $(P<0.05)$ IAc on T60, than GPX 1 and $5 U$, and cysteine $0.5 \mathrm{mM}$. The PMM from a stallion on T60 was higher $(P<0.05)$ than those of two stallions. In sperm kinematic, VCL and VAP were higher $(P<0.05)$ at T0 compared to T60 for the control group, and one stallion showed larger $(P<0.05)$ kinematic values than other animals. It is concluded that the addition of glutathione peroxidase at concentrations $1 U$ and $5 U$, and cysteine, at concentrations of $0.5 \mathrm{mM}$ and $1 \mathrm{mM}$, does not interfere with the integrity of cryopreserved equine sperm, but preserves the kinetic parameters VCL and VAP after 60 minutes of incubation. It should be noted also that the stallion has a strong influence on sperm characteristics post-freezing.
\end{abstract}

Keywords: equine, antioxidants, spermatozoa, cryopreservation

Recebido em 4 de maio de 2011

Aceito em 6 de setembro de 2012

*Autor para correspondência (corresponding author)

E-mail: mpguerra@dmv.ufrpe.br 


\section{INTRODUÇÃO}

O uso de sêmen congelado na espécie equina apresenta-se como uma importante biotécnica aplicada ao manejo reprodutivo dessa espécie (Ball et al., 2001). Durante o processo de congelação, quando exposto a baixas temperaturas, o espermatozoide equino produz maior quantidade de espécies reativas ao oxigênio (ROS) se comparado com o processo de refrigeração (Guerra et al., 2004). Desse modo, causa estresse oxidativo (Ball, 2008) e danos à membrana celular, reduzindo a motilidade e a longevidade espermática, além de causar danos diretos ao DNA espermático (Reghini et al., 2010).

Os antioxidantes são inibidores das ROS na sua formação ou no mecanismo de ação, presentes no espermatozoide e no plasma seminal, atuando de forma independente ou sinérgica (Aurich, 2008). A principal defesa antioxidante é realizada pela ação da catalase (CAT), superóxido dismutase (SOD), glutationa reduzida (GR) e glutationa peroxidase (GPx), presentes no espermatozoide e no plasma seminal (Varner, 2007; Andrade et al., 2010). A GPx foi relacionada à infertilidade de homens (Pons-Rejraji et al., 2009). Nos bovinos, sua redução determinou baixa da capacidade fertilizante dos espermatozoides (Baumber et al., 2005). E, nos equinos, verificou-se correlação positiva entre motilidade $\mathrm{e}$ integridade de membrana com a presença de GPx e catalase, indicando que esses antioxidantes contribuem para o aumento inicial da motilidade e da integridade da membrana espermática (Pagl et al., 2006). A cisteína, proteína que nos equinos encontra-se presente nas secreções da ampola do ducto deferente e da vesícula seminal, está envolvida nos processos de espermatogênese, maturação espermática e, possivelmente, penetração do espermatozoide na zona pelúcida (Varner, 2007).

Assim, este trabalho teve o objetivo de analisar o efeito da adição de diferentes concentrações dos antioxidantes GPx e cisteína ao diluidor de congelação do sêmen equino sobre a viabilidade in vitro dos espermatozoides.

\section{MATERIAL E MÉTODOS}

Foram utilizados cinco garanhões da raça Quarto-de-Milha, com idade variando de 5 a 21 anos, alimentados com feno de capim Tifton (Cynodon dactilon), ração concentrada com 22\% de proteína bruta (PB), suplemento mineral e água ad libitum. Foram realizadas, no mês de julho, cinco colheitas de sêmen por animal, com intervalo de 48 horas, utilizando vagina artificial, modelo Botucatu (Biotech, Botucatu, São Paulo, Brasil), e uma fêmea em cio como manequim, totalizando 25 ejaculados.

As amostras de sêmen foram avaliadas quanto à motilidade (0-100\%), ao vigor (0-5) e à concentração espermática $\left(\begin{array}{lll}1 & \mathrm{x} & 10^{6}\end{array}\right.$ espermatozoides/mL), segundo o CBRA (1998), em microscópio de Contraste de Fase (Olympus, Tóquio, Japão), com aumento de 40x. Imediatamente após as análises, as amostras de sêmen foram processadas, diluídas na proporção de 1:1 (sêmen:diluidor) com meio Botu Sêmen (Biotech, Botucatu, SP, Brasil), centrifugadas (600 x g) durante 10 minutos (Papa et al., 2005), desprezado o sobrenadante e ressuspenso o pellet com meio de congelação Botu Crio (Biotech, Botucatu, SP, Brasil), acrescido dos antioxidantes GPx e cisteína, de acordo com os grupos experimentais: $\mathrm{G} 1=$ controle $(\mathrm{sem}$ antioxidantes); G2 = 1U de GPx; G3 = 5U de GPx; G4 = 0,5 mM de N-Acetyl-Cisteína; e G5 = $1 \mathrm{mM}$ de N-Acetyl-Cisteína, segundo Sariözkan et al. (2009). Os antioxidantes (GPx e cisteína) e demais produtos químicos utilizados neste experimento foram adquiridos da Sigma-Aldrich $\mathrm{Co}^{\circledR}$ (St Louis, Missouri, USA). O sêmen foi envasado em palheta $(0,5 \mathrm{~mL})$, na concentração de $150 \times 10^{6}$ espermatozoides/palheta (Clulow et al., 2008), e congelado em sistema automatizado (TK 3000, TK Tecnologia em congelação, Uberaba, Brasil). A curva de congelação utilizada determinou redução de temperatura de $0,5^{\circ} \mathrm{C}$ por minuto até atingir $5^{\circ} \mathrm{C}$ e, em seguida, redução de $1^{\circ} \mathrm{C}$ por minuto até $-120^{\circ} \mathrm{C}$. A seguir, as amostras foram armazenadas em botijão criobiológico $\left(-196^{\circ} \mathrm{C}\right)$. As amostras foram descongeladas utilizando-se banho-maria a $37^{\circ} \mathrm{C}$ por 30 segundos.

Para avaliação da integridade de membrana plasmática, utilizou-se o método de coloração dupla com diacetato de carboxifluoresceína (DCF) e iodeto de propídeo (IP), segundo Coleto et al. (2002), em que 200 espermatozoides foram avaliados em microscópio de epifluorescência (Carl Zeiss, Göttingen, Alemanha), com aumento de 400x, usando filtro de emissão DBP 580- 
630nm e excitação DBP 485-520nm, e classificados com membrana intacta, quando corados em verde, e com membranas danificadas, quando corados em vermelho. A integridade de acrossoma foi avaliada utilizandose o conjugado isotiocionato de fluoresceínaPsium sativum (FITC-PSA), segundo Celegni et al. (2010), sendo 200 espermatozoides avaliados em microscópio de epifluorescência, com aumento de 1000x, com filtro de emissão LP $515 \mathrm{~nm}$ e BP 450-490nm para excitação, classificados como lesados, quando corados em verde, e intactos, sem coloração.

O potencial de membrana mitocondrial dos espermatozoides foi determinado pela utilização do fluorocromo catiônico lipofílico JC-1 (Guthrie e Welch, 2006), e avaliado em microscópio de epifluorescência, com aumento de 1000x, sob óleo de imersão, usando filtro de emissão LP $515 \mathrm{~nm}$ e BP 450-490nm para excitação. Espermatozoides $(n=200)$ com a peça intermediária corada em laranja foram classificados com alto potencial de membrana mitocondrial, e corada em verde classificados com baixo potencial de membrana mitocondrial.

Para avaliação da cinética espermática, as amostras descongeladas foram diluídas em solução de Ringer com Lactato, para facilitar a visualização e captação dos campos na Câmara de Makler $^{\circledR}$ (Sefi Medical Instrument, Haifa, Israel), segundo Mortimer (2000), previamente aquecida a $37^{\circ} \mathrm{C}$, colocada no microscópio de contraste de fase (Nikon ${ }^{\mathrm{TM}}$ H5505, Eclipse 50i, Japão), e as imagens capturadas por uma vídeocâmera (Basler Vision Tecnologie ${ }^{\mathrm{TM}}$ A312FC, Ahrensburg, Alemanha). Pelo sistema CASA (Sperm Class Analyzer - SCA ${ }^{\mathrm{TM}}$, Microptics, S.L., Version 3.2.0, Barcelona, Espanha), foram avaliados os seguintes parâmetros: motilidade total (MT), motilidade progressiva (MP), linearidade (LIN) e retilinearidade (STR), expressas em porcentagem (\%); velocidade rápida (VR), velocidade curvilinear (VCL), velocidade em linha reta (VSL) e velocidade média do percurso (VAP), expressas em micrômetros por segundos $(\mu \mathrm{m} / \mathrm{s})$; amplitude do descolamento lateral da cabeça espermática $(\mathrm{ALH})$, expressa em micrômetros $(\mu \mathrm{m})$; e frequência do batimento flagelar cruzado (BCF), expressa em Hertz (Hz).
Os dados foram analisados pelo teste de Kolmogorov-Smirnov para determinar a normalidade dos dados, submetidos ao modelo split-plot de análise de variância, com contraste de médias pelo teste de Tukey. Foi utilizado o procedimento PROC MIXED do SAS (2005) para medidas repetidas. Análise de correlação de Pearson foi realizada para verificar o grau de relação entre pares de variáveis, segundo Little e Hills (1978), ficando estabelecida a existência de correlação de alta intensidade entre as variáveis quando $r>0,60$; média intensidade quando $0,30<\mathrm{r}<0,60$; e de baixa intensidade quando $\mathrm{r}<0,30$, com os valores expressos em média e desvio-padrão, sendo $\mathrm{o}$ valor de $\mathrm{P}<0,05$ significante. Para cada garanhão, foi obtida uma média de cinco repetições/animal, objetivando-se diminuir a variabilidade dos fatores, tratamento e tempo.

\section{RESULTADOS}

Os resultados das análises espermáticas pós-descongelação, utilizando as sondas fluorescentes (Tab. 1), mostraram que não houve diferença significativa $(\mathrm{P}>0,05)$ nos percentuais de gametas com membrana plasmática íntegra (IMP), assim como com alto potencial de membrana mitocondrial (aPMM), das amostras do grupo controle e demais grupos, em cada tempo de avaliação ( 0 e 60 minutos), bem como entre 0 (T0) e 60 minutos (T60). Entretanto, observou-se maior $(\mathrm{P}<0,05)$ porcentagem de espermatozoides com acrossomas íntegros (IAc) nas amostras congeladas dos grupos GPX $5 \mathrm{U}$ e cisteína $0,5 \mathrm{mM}$, imediatamente após a descongelação (T0), quando comparados às amostras avaliadas 60 minutos depois (T60).

Além disso, observou-se que, 60 minutos após a descongelação (T60), o grupo suplementado com cisteína $(1 \mathrm{mM})$ não diferiu $(\mathrm{P}>0,05)$ do grupo controle, mas apresentou maior $(\mathrm{P}<0,05)$ porcentagem de gametas com acrossomas íntegros do que dos grupos GPx 1 e 5U e cisteína $0,5 \mathrm{mM}$ (Tab. 1). A análise individual dos reprodutores mostrou que $\mathrm{o}$ garanhão 4 apresentou menor $(\mathrm{P}<0,05)$ porcentagem de espermatozoides com membrana plasmática íntegra em relação aos demais cavalos, tanto imediatamente após a descongelação (T0) quanto 60 minutos após (T60) (Tab. 2). 
Tabela 1. Valores de média e desvio-padrão de espermatozoides com membrana plasmática (IMP) e acrossomas (IAc) íntegros, e alto potencial de membrana mitocondrial (aPMM) das amostras de sêmen equino congeladas em Botu Sêmen suplementado com GPx e cisteína, imediatamente após a congelação (T0) e 60 minutos depois (T60)

\begin{tabular}{ccccc} 
Grupo & $\begin{array}{c}\text { Tempo } \\
\text { (min.) }\end{array}$ & IMP $(\%)$ & IAc (\%) & aPMM (\%) \\
Controle & 0 & $60,01 \pm 12,89$ & $85,51 \pm 1,92$ & $62,27 \pm 7,92$ \\
& 60 & $54,93 \pm 9,87$ & $82,41 \pm 4,46 \mathrm{AB}$ & $48,47 \pm 9,83$ \\
GPx 1U & 0 & $56,91 \pm 8,04$ & $87,28 \pm 5,51$ & $57,37 \pm 6,82$ \\
& 60 & $53,10 \pm 4,38$ & $76,23 \pm 3,70 \mathrm{C}$ & $53,28 \pm 13,08$ \\
GPx 5U & 0 & $59,05 \pm 8,56$ & $84,53 \pm 3,45 \mathrm{a}$ & $59,47 \pm 6,71$ \\
& 60 & $50,33 \pm 7,42$ & $79,86 \pm 2,95 \mathrm{bBC}$ & $51,58 \pm 14,32$ \\
Cisteína 0,5mM & 0 & $49,93 \pm 8,58$ & $82,10 \pm 2,92 \mathrm{a}$ & $56,72 \pm 5,06$ \\
& 60 & $56,45 \pm 8,50$ & $77,05 \pm 4,62 \mathrm{bBC}$ & $55,02 \pm 13,63$ \\
& & & & \\
Cisteína 1mM & 0 & $47,50 \pm 13,86$ & $82,56 \pm 6,69$ & $54,04 \pm 4,27$ \\
& 60 & $55,32 \pm 11,26$ & $86,98 \pm 4,31 \mathrm{~A}$ & $57,04 \pm 7,66$ \\
\hline Tempo & & 0,7470 & 0,0060 & 0,0742 \\
\hline T 0 nos tratamentos & & 0,2738 & 0,3610 & 0,3425 \\
\hline
\end{tabular}

*Letras minúsculas distintas na mesma coluna indicam diferenças $(\mathrm{P}<0,05)$ entre tempos dentro de cada grupo; **Letras maiúsculas distintas na mesma coluna indicam diferenças $(\mathrm{P}<0,05)$ entre grupos no tempo de 60 minutos após a descongelação.

Tabela 2. Valores de média e desvio-padrão de espermatozoides com membrana plasmática (IMP) e acrossomas (IAc) íntegros, e alto potencial de membrana mitocondrial (aPMM) por animal, das amostras de sêmen equino congeladas em Botu Crio suplementado com GPx e cisteína, imediatamente após a congelação (T0) e 60 minutos depois (T60)

\begin{tabular}{|c|c|c|c|c|}
\hline Animal & $\begin{array}{c}\text { Tempo } \\
\text { (min) }\end{array}$ & $\operatorname{IMP}(\%)$ & IAc $(\%)$ & $\operatorname{aPMM}(\%)$ \\
\hline \multirow[t]{2}{*}{1} & 0 & $53,20 \pm 9,87 a$ & $82,63 \pm 4,05$ & $57,77 \pm 7,11$ \\
\hline & 60 & $59,60 \pm 5,29 \mathrm{~A}$ & $78,88 \pm 8,88$ & $43,83 \pm 6,63 \mathrm{C}$ \\
\hline \multirow[t]{2}{*}{2} & 0 & $64,47 \pm 8,06 \mathrm{a}$ & $84,60 \pm 3,80$ & $60,16 \pm 8,15$ \\
\hline & 60 & $54,45 \pm 3,75 \mathrm{~A}$ & $80,16 \pm 4,80$ & $46,05 \pm 7,78 \mathrm{BC}$ \\
\hline \multirow[t]{2}{*}{3} & 0 & $55,76 \pm 4,20 \mathrm{a}$ & $83,18 \pm 3,55$ & $56,88 \pm 4,58$ \\
\hline & 60 & $58,65 \pm 6,20 \mathrm{~A}$ & $80,54 \pm 3,95$ & $58,35 \pm 8,25 \mathrm{AB}$ \\
\hline \multirow[t]{2}{*}{4} & 0 & $40,70 \pm 9,17 b$ & $84,15 \pm 5,34$ & $59,55 \pm 3,00$ \\
\hline & 60 & $41,53 \pm 5,25 \mathrm{~B}$ & $80,09 \pm 4,16$ & $53,20 \pm 14,70 \mathrm{ABC}$ \\
\hline \multirow[t]{2}{*}{5} & 0 & $59,26 \pm 8,33 a$ & $84,55 \pm 7,38$ & $55,50 \pm 8,97$ \\
\hline & 60 & $55,90 \pm 5,07 \mathrm{~A}$ & $78,80 \pm 2,80$ & $63,95 \pm 5,60 \mathrm{~A}$ \\
\hline T 0 nos tratamentos & & 0,0026 & 0,6207 & 0,8043 \\
\hline T 60 nos tratamentos & & 0,0001 & 0,5608 & 0,0130 \\
\hline
\end{tabular}

*Letras minúsculas distintas na mesma coluna indicam diferenças $(\mathrm{P}<0,05)$ entre animais, no tempo de 0 minuto após a descongelação; **Letras maiúsculas distintas na mesma coluna indicam diferenças $(\mathrm{P}<0,05)$ entre animais, no tempo de 60 minutos após a descongelação. 
Após a descongelação do sêmen, nos parâmetros cinéticos MT, MP, VR, VSL, LIN, STR, WOB, $\mathrm{ALH}$ e BCF, não foi observada diferença $(\mathrm{P}>0,05)$ entre o grupo controle e os grupos experimentais nos tempos avaliados (Tab. 3). Contudo, o VCL e VAP apresentaram redução $(\mathrm{P}<0,05)$ nas amostras do grupo controle entre o T0 e o T60. Esse fato não foi observado nos grupos suplementados com antioxidantes. Todavia, a análise da cinética espermática de cada animal (Tab. 4) evidenciou diferenças significativas $(\mathrm{P}<0,05)$ em relação aos tempos e grupos experimentais. $\mathrm{O}$ animal 4 apresentou maiores $(\mathrm{P}<0,05)$ valores de MT, MP, VR, VCL, VSL, VAP e ALH do que os outros animais.

Tabela 3. Valores de média e desvio-padrão da cinética de espermatozoides equinos submetidos a congelação após diluição em Botu Cio (controle), suplementados com GPx e cisteína, imediatamente após a descongelação T0 e 60 minutos depois (T60)

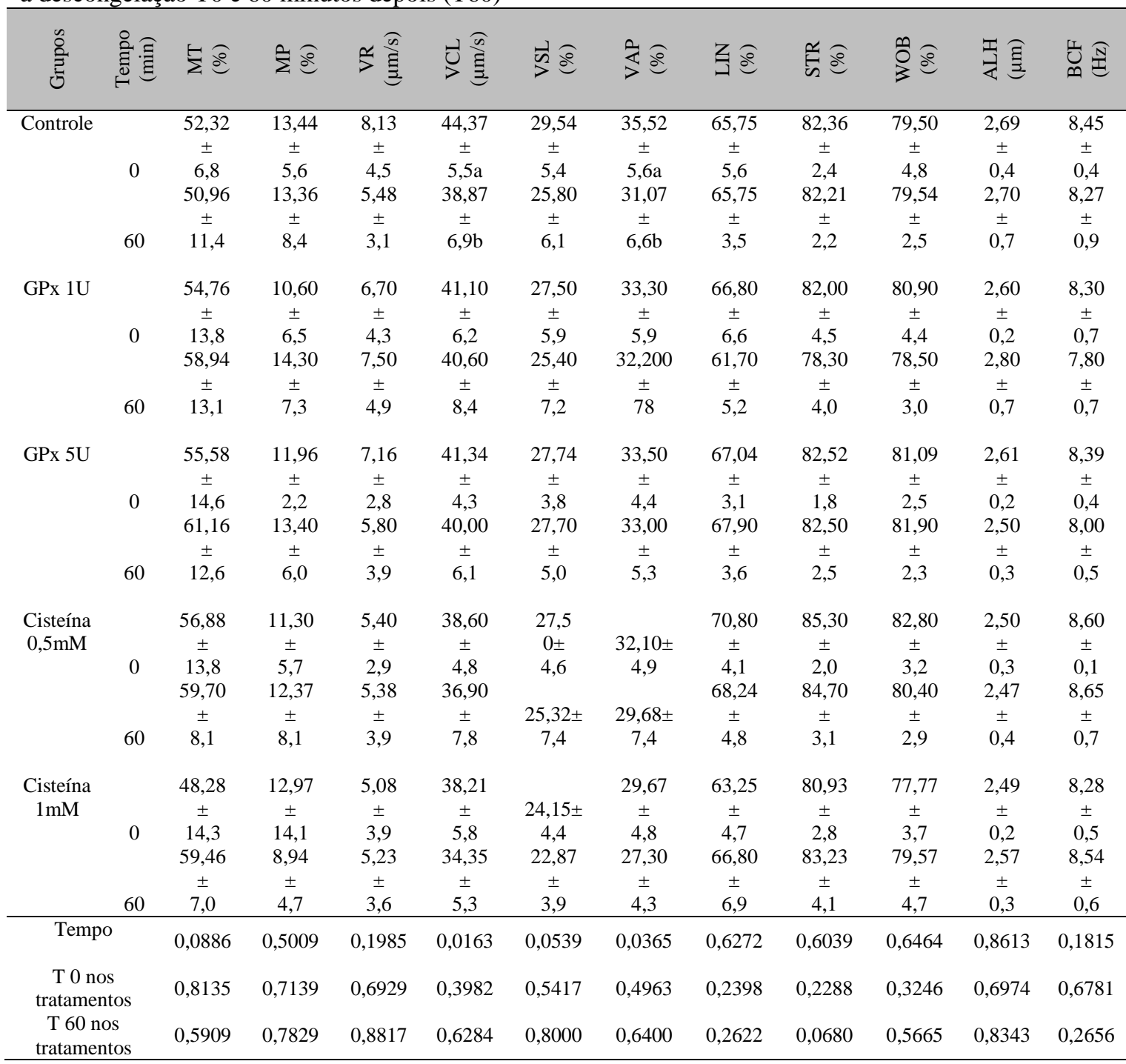

$\mathrm{MT}=$ motilidade total; $\mathrm{MP}=$ motilidade progressiva; $\mathrm{VR}=$ velocidade rápida; $\mathrm{VCL}=$ velocidade curvilinear; $\mathrm{VSL}=$ velocidade em linha reta; $\mathrm{VAP}=$ velocidade média do percurso; $\mathrm{LIN}=$ linearidade; $\mathrm{STR}=$ retilinearidade; $\mathrm{WOB}=$ índice de oscilação ou wobble; ALH = amplitude do deslocamento lateral da cabeça do espermatozoide; $\mathrm{BCF}=$ batimento flagelar cruzado. *Letras diferentes na mesma coluna indicam diferença $(\mathrm{P}<0,05)$ entre tempos, dentro de cada grupo. 
Tabela 4. Valores de média e desvio-padrão da cinética, por animal, de espermatozoides equinos submetidos a congelação após diluição em BotuCrio® (controle), suplementado com GPx e cisteína, imediatamente após a congelação (T0) e 60 minutos depois (T60)

\begin{tabular}{|c|c|c|c|c|c|c|c|c|c|c|c|}
\hline 点 & $\sum \overparen{e}$ & $\sum \sqrt{e}$ & 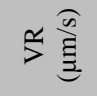 & 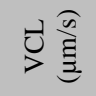 & $\overrightarrow{5} \sqrt{2}$ & $\underset{>}{>}$ & Z & 况 & $\overbrace{3}^{\infty} \stackrel{8}{e}$ & 焉 & $\bigcup_{n}^{\underline{I}} \widehat{\mathbb{y}}$ \\
\hline \multirow{3}{*}{1} & 47,52 & 6,93 & 3,74 & 35,69 & 23,89 & 28,66 & 66,67 & 82,74 & 80,14 & 2,29 & 7,66 \\
\hline & \pm & \pm & \pm & \pm & \pm & \pm & \pm & \pm & \pm & \pm & \pm \\
\hline & $9,13 b$ & $2,78 b$ & $1,63 b$ & $5,47 \mathrm{c}$ & $4,49 b c$ & $5,04 \mathrm{c}$ & $5,09 \mathrm{ab}$ & $3,23 \mathrm{ab}$ & 3,56 & $0,25 \mathrm{c}$ & $0,53 \mathrm{c}$ \\
\hline \multirow{3}{*}{2} & 52,90 & 11,08 & 5,28 & 39,88 & 26,72 & 32,40 & 66,56 & 81,67 & 80,97 & 2,40 & 8,28 \\
\hline & \pm & \pm & \pm & \pm & \pm & \pm & \pm & \pm & \pm & \pm & \pm \\
\hline & $6,77 b$ & $2,73 b$ & $1,68 b$ & $3,78 b$ & $3,28 b$ & $3,55 b$ & $4,36 a b$ & $3,14 b$ & 2,90 & $0,07 b c$ & $0,45 b$ \\
\hline \multirow{3}{*}{3} & 52,53 & 9,81 & 4,29 & 36,58 & 24,20 & 29,38 & 65,33 & 81,50 & 79,79 & 2,67 & 8,29 \\
\hline & \pm & \pm & \pm & \pm & \pm & \pm & \pm & \pm & \pm & \pm & \pm \\
\hline & $10,18 b$ & $5,61 \mathrm{~b}$ & $1,39 b$ & $4,19 b c$ & $4,88 \mathrm{bc}$ & $4,87 \mathrm{bc}$ & $5,69 \mathrm{~b}$ & $2,91 \mathrm{~b}$ & 4,32 & $0,54 \mathrm{ac}$ & $0,47 b$ \\
\hline \multirow{3}{*}{4} & 69,70 & 22,10 & 12,41 & 48,18 & 33,84 & 39,55 & 70,03 & 85,10 & 81,97 & 2,70 & 8,63 \\
\hline & \pm & \pm & \pm & \pm & \pm & \pm & \pm & \pm & \pm & \pm & \pm \\
\hline & $5,38 \mathrm{a}$ & $6,14 \mathrm{a}$ & $2,30 \mathrm{a}$ & $3,45 \mathrm{a}$ & $2,96 a$ & $3,06 \mathrm{a}$ & $3,79 \mathrm{a}$ & $2,25 \mathrm{a}$ & 2,50 & $0,14 \mathrm{a}$ & $0,19 \mathrm{a}$ \\
\hline \multirow{3}{*}{5} & 56,37 & 11,34 & 5,21 & 36,87 & 23,14 & 28,72 & 63,49 & 81,00 & 78,12 & 2,89 & 8,76 \\
\hline & \pm & \pm & \pm & \pm & \pm & \pm & \pm & \pm & \pm & \pm & \pm \\
\hline & $12,33 \mathrm{~b}$ & $5,89 \mathrm{~b}$ & $1,79 \mathrm{~b}$ & $4,39 \mathrm{bc}$ & $2,18 \mathrm{c}$ & $3,18 \mathrm{c}$ & $4,99 \mathrm{~b}$ & $3,85 \mathrm{~b}$ & 3,35 & $0,35 \mathrm{a}$ & $0,57 \mathrm{a}$ \\
\hline "P" & 0,0001 & 0,0001 & 0,0001 & 0,0001 & 0,0001 & 0,0001 & 0,0472 & 0,0184 & 0,1364 & 0,0012 & 0,0001 \\
\hline
\end{tabular}

MT = motilidade total; $\mathrm{MP}=$ motilidade progressiva; $\mathrm{VR}=$ velocidade rápida; $\mathrm{VCL}=$ velocidade curvilinear; $\mathrm{VSL}=$ velocidade em linha reta; VAP = velocidade média do percurso; LIN = linearidade; STR = retilinearidade; WOB = índice de oscilação ou wobble; $\mathrm{ALH}=$ amplitude do deslocamento lateral da cabeça do espermatozoide; $\mathrm{BCF}=$ batimento flagelar cruzado. *Letras diferentes na mesma coluna indicam diferença $(\mathrm{P}<0,05)$ entre animais.

A análise do coeficiente de correlação de Pearson verificou alto grau de relação positiva $(\mathrm{r}>0,60 ; \mathrm{P}<0,0001)$ entre pares de variáveis, como: MP x MT, VR, VCL, VSL e VAP; VR x VCL, VSL e VAP; VCL x VSL e VAP; VSL $x$ VAP, LIN e WOB; LIN x STR e WOB; STR x WOB. A motilidade total apresentou moderada relação positiva $(0,30>\mathrm{r}<0,60 ; \mathrm{P}<0,05) \mathrm{com}$ VR, VCL, VSL, VAP, LIN, STR e WOB, bem como MP x ALH; VR x VM e STR; VCL x LIN e WOB; VSL x STR; VAP x LIN, STR e WOB; BCF x STR e ALH (Tab. 5). Também foi observada relação significativa entre alguns parâmetros do CASA $(0,30>r<0,60 ; \mathrm{P}<0,05)$ e IMP e IAc. Entre eles destacaram-se: IMP x VR, VCL, VSL, VAP e MT; IAc x VR, VCL e VSL (Tab. 5).

Tabela 5. Coeficiente de correlação de Pearson entre os parâmetros do sêmen equino submetido a congelação após diluição em Botu Crio (controle) suplementado com GPx e cisteína

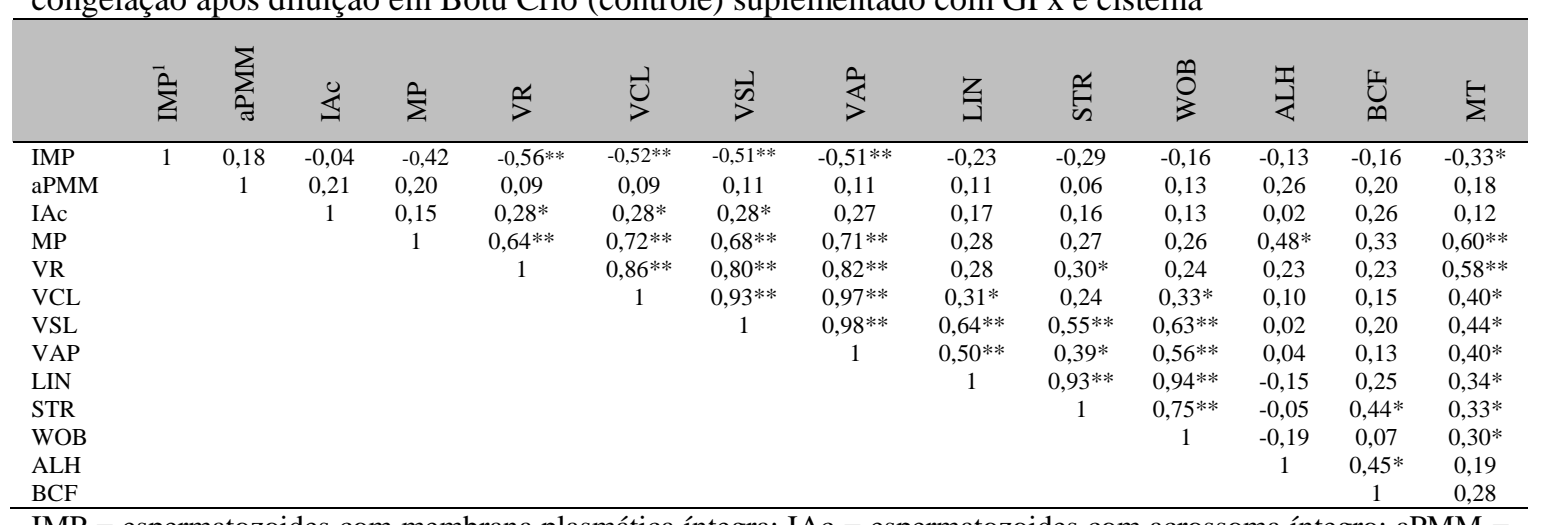

IMP = espermatozoides com membrana plasmática íntegra; IAc = espermatozoides com acrossoma íntegro; aPMM = espermatozoides com alto potencial de membrana mitocondrial; MP = motilidade progressiva; $\mathrm{VR}=$ velocidade rápida; $\mathrm{VCL}=$ velocidade curvilinear; VSL = velocidade em linha reta; VAP = velocidade média do percurso; $\mathrm{LIN}=$ linearidade; $\mathrm{STR}=$ retilinearidade; $\mathrm{WOB}=$ índice de oscilação ou wobble; $\mathrm{ALH}=$ amplitude do deslocamento lateral da cabeça do espermatozoide; $\mathrm{BCF}=$ batimento flagelar cruzado; $\mathrm{MT}=$ motilidade total. Valores estatisticamente significativos quando $* \mathrm{P}<0,05$ e $* * \mathrm{P}<0,0001$. 


\section{DISCUSSÃO}

O fato de os resultados obtidos após análise de espermatozoides equinos congelados com GPx e cisteína não terem evidenciado diferenças significativas no percentual desses gametas com membrana plasmática íntegra (IMP) e alto potencial de membrana mitocondrial (aPMM), assim como entre os animais utilizados, pode estar relacionado às concentrações dos antioxidantes, presença de agentes antioxidantes no meio de congelação utilizado ou, ainda, devido a diferentes ROS e seus respectivos mecanismos de ação no sêmen pósdescongelação (Watson, 2000).

O efeito positivo da adição de $1 \mathrm{mM}$ de cisteína na porcentagem de espermatozoides com acrossomas íntegros (IAc), no tempo T60 pósdescongelação, em relação aos grupos GPx 1 e $5 \mathrm{U}$ e cisteína $0,5 \mathrm{mM}$, pode estar relacionado à inibição da fosforilação da tirosina que atua na capacitação espermática, através do bloqueio dos canais de íons na membrana plasmática (Varner, 2007), melhorando a integridade da membrana espermática pós-descongelação (Pagl et al., 2006), sem eliminar a presença de ROS (Michael et al., 2008). Esperava-se, também, que esses antioxidantes promovessem maior porcentagem de gametas com aPMM, devido à maior proteção às mitocôndrias (Sariozkan et al., 2009), resultando em maior motilidade (MT e MP).

A adição dos antioxidantes (GPx e cisteína) não resultou em efeito positivo no percentual de espermatozoides com membrana plasmática íntegra e com alto potencial de membrana mitocondrial após o processo de congelação do sêmen de equino. Esse resultado ratifica os relatos de Reghini et al. (2010), que, ao adicionarem cisteína ao diluente de refrigeração de sêmen equino, em concentrações (1mM, $5 \mathrm{mM}, 10 \mathrm{mM}, 15 \mathrm{mM}$ e $20 \mathrm{mM}$ ) diferentes das utilizadas no presente estudo, não observaram melhoria dos percentuais de gametas membrana plasmática íntegra, assim como dos parâmetros cinéticos (MT e MP), após 24 horas de refrigeração com temperaturas que variaram de 5 $-15^{\circ} \mathrm{C}$. No entanto, ressalta-se que o processo de refrigeração determina menor produção de ROS do que a congelação de sêmen (Guerra et al., 2004). Apesar de o estudo de integridade de acrossoma não ter evidenciado diferença entre o grupo controle e o com cisteína $1 \mathrm{mM}$, observa-se percentual numericamente maior no grupo tratado, evidenciando efeito positivo da adição desse antioxidante.

O menor percentual de espermatozoides com membrana plasmática íntegra no T60 observado no animal 4 provavelmente determinou hiperativação celular, ocasionada pelo rápido retorno do metabolismo do oxigênio, provocando aumento na produção de ROS (Ball, 2008). Além disso, esse resultado pode ser explicado pelas diferenças entre indivíduos, ejaculados, metabolismo e bioquímica espermática, que alteram os parâmetros seminais (Loomis et al., 2008), sendo a proporção de espermatozoides com membranas danificadas um indicativo de fertilidade reduzida em garanhões (Blottner et al., 2001).

A ausência de diferença entre os grupos experimentais, com relação aos parâmetros avaliados por meio do sistema CASA - MT, MP, VR, VSL, LIN, STR, WOB, ALH e BCF - nos tempos - T0 e T60 - analisados, é contrária aos resultados de Schober et al. (2007), ao demonstrarem que a criopreservação determina redução da motilidade espermática pósdescongelação, devido a danos causados às mitocôndrias, reduzindo, assim, a síntese de energia (ATP), necessária para a movimentação dos espermatozoides no trato genital da fêmea. Esses danos nas mitocôndrias determinam mudanças na trajetória linear e redução da velocidade, sem aumentar a proporção de espermatozoides estáticos (Ortega-Ferrusola et al., 2009), o que explicaria a redução da VCL e VAP dos espermatozoides do grupo controle nos tempos analisados.

As características de MT, MP, VR, VSL, VAP e ALH, maiores no animal 4, em comparação às dos demais animais do experimento, podem estar relacionadas à expressão dos marcadores apoptóticos nos garanhões e ejaculados, que diferem na sua congelabilidade, uma vez que maior concentração desses marcadores pode determinar pior resultado pós-descongelação (Ball, 2008; Ortega-Ferrusola et al., 2009). 


\section{CONCLUSÕES}

A adição de glutationa peroxidase, nas concentrações de $1 \mathrm{U}$ e $5 \mathrm{U}$, e de cisteína, nas concentrações de $0,5 \mathrm{mM}$ e $1 \mathrm{mM}$, não interferem na integridade de espermatozoides criopreservados de equinos, mas preservam os parâmetros cinéticos de VCL e VAP após 60 minutos de incubação. Ressalta-se, ainda, que no garanhão ocorreu influência da pós-congelação nas características espermáticas.

\section{AGRADECIMENTOS}

À FACEPE, pela concessão da bolsa e recursos financeiros; à CAPES e ao CNPq, pelo apoio financeiro; e ao Haras RC (Ingá - PB), por ceder os animais para o experimento.

\section{REFERÊNCIAS}

ANDRADE, E.R.; MELO-STERZA, F.A.; SENEDA, M.M. et al. Consequências da produção das espécies reativas de oxigênio na reprodução e principais mecanismos antioxidantes. Rev. Bras. Reprod. Anim., v.34, p.79-85, 2010.

AURICH, C. Recent advances in cooled-semen technology. Anim. Reprod. Sci., v.107, p.268275,2008 .

BALL, B.A. Oxidative stress, osmotic stress and apoptosis: Impacts on sperm function and preservation in the horse. Anim. Reprod. Sci., v.107, p.260-267, 2008.

BALL, B.A.; MEDINA, V.; GRAVANCE, C.G. et al. Effect of antioxidants on preservation of motility, viability, and acrosomal integrity of equine spermatozoa during store at 5 degrees $\mathrm{C}$. Theriogenology, v.56, p.577-589, 2001.

BAUMBER, J.; BALL, B.A.; LINFOR, J.J. Assessment of the cryopreservation of equine spermatozoa in the presence of enzyme scavengers and antioxidants. Am. J. Vet. Res., v.66, p.772-779, 2005.

BLOTTNER, S.; WARNKE, C.; TUCHSCHERER, A. et al. Morphological and functional changes of stallion spermatozoa after cryopreservation during breeding and non-breeding season. Anim. Reprod. Sci., v.65, p.75-88, 2001.
CBRA. Manual para exame andrológico e avaliação do sêmen animal. 2.ed., Belo Horizonte: Colégio Brasileiro de Reprodução Animal, 1998. 49p.

CELEGHINI, E.C.C.; NASCIMENTO, J.; RAPHAEL, C.F. et al. Simultaneous assessment of plasmatic, acrosomal, and mitochondrial membranes in ram sperm by fluorescent probes. Arq. Bras. Med. Vet. Zootec., v.62, p.536-543, 2010.

CLULOW, J.R.; MANSFIELD, L.J.; MORRIS, L.H.A. et al. A comparison between freezing methods for the cryopreservation of stallion spermatozoa. Anim. Reprod. Sci., v.108, p.298308, 2008.

COLETO, Z.F.; GUERRA, M.M.P.; BATISTA, A.M. Avaliação do sêmen congelado de caprinos com drogas fluorescentes. Rev. Bras. Med. Vet., v.24, p.101-104, 2002.

GUERRA, M.M.P.; EVANS, G.; MAXWELL, W.M.C. Papel dos oxidantes e anti-oxidantes na Andrologia. Rev. Bras. Reprod. Anim., v.28, p.187-195, 2004.

GUTHRIE, H.D.; WELCH, G.R. Determination of intracellular reactive oxygen species and high mitochondrial membrane potential in Percolltreated viable boar sperm using fluorescenceactivated flow cytometry. J. Anim. Sci., v.84, p.2089-2100, 2006.

LITTLE, T.M.; HILLS, F.J. Agricultural experimentation: design and analysis. New York: John Wiley, 1978. 350 p.

LOOMIS, P.R.; GRAHAM, J.K. Commercial semen freezing: Individual male variation in cryosurvival and the response of stallion sperm to customized freezing protocols. Anim. Reprod. Sci., v.105, p.119-128, 2008.

MICHAEL, A.J.; ALEXOPOULOS, C.; PONTIKI, E.A. et al. Effect of N-Acetyl-L-cysteine supplementation in semen extenders on semen quality and reactive oxygen species of chilled canine spermatozoa. Reprod. Dom. Anim., v.120, p.1-7, 2008.

MORTIMER, S.T. CASA - Practical Aspects. J. Androl., v.21, p.515-524, 2000. 
ORTEGA-FERRUSOLA, C.; GARCÍA, B.M.; GALLARDO-BOLAÑOS, J.M. et al. Apoptotic markers can be used to forecast the freezeability of stallion spermatozoa. Anim. Reprod. Sci., v.114, p.393-403, 2009.

PAGL, R.; AURICH, C.; KANKOFER, M. Antioxidative status and semen quality during cooled storage in stallions. J. Vet. Med., v.53, p.486-489 2006.

PAPA, F.O.; MELO, C.M.; DELL'AQUA Jr., J.A. et al. Inovações Metodológicas na Biotecnologia de refrigeração e congelação de sêmen equino. Acta Sci. Vet., v.33, p.19-27, 2005.

PONS-REJRAJI, H.; SION, B.; SAEZ, F. et al. Role of reactive oxygen species (ROS) on human spermatozoa and male infertility. Gynecol. Obstet. Fertil., v.28, p.203-213, 2009.

REGHINI, M.F.S.; ULIANI, R.C.; MONTEIRO, G.A. et al. Utilização da N-Acetilcisteína na conservação do sêmen equino à $5^{\circ}$ e $15^{\circ} \mathrm{C}$. In: CONFERENCIA ANUAL DA ASSOCIAÇÃO BRASILEIRA DOS VETERINÁRIOS DE EQUÍDEOS, 11., 2010, São Paulo. Anais... São Paulo, 2010. p.326-327.
SAS. SAS user's guide, statistics version. Cary, NC: Statistical Analysis System Institute Inc., 2005.

SARIÖZKAN, S.; BUCAK, M.N.; TUNCER, P.B. et al. The influence of cysteine and taurine on microscopic-oxidative stress parameters and fertilizing ability of bull semen following cryopreservation. Cryobiology, v.58, p.134-138, 2009.

SCHOBER, D.; AURICH, C.; NOHL, H. et al. Influence of cryopreservation on mitochondrial functions in equine spermatozoa. Theriogenology, v.68, p.745-754, 2007.

VARNER, D. From a Sperm`s Eye View Revisiting Our Perception of This Intriguing cell. In: ANNUAL CONVENTION OF AMERICAN ASSOCIATION OF EQUINE PRATICIONERS, 53., Orlando, 2007. Proceedings... Orlando, 2007 p. 104-177.

WATSON, P.F. The causes of reduced fertility with cryopreserved semen. Anim. Reprod. Sci., v.60-61, p.481-492, 2000. 